University of Wollongong

Research Online

Faculty of Engineering - Papers (Archive)

Faculty of Engineering and Information

Sciences

2001

\title{
Magneto-optical images of Ag/Bi-2223 tapes processed by flat rolling, "sandwich" rolling and pressing
}

Hua-Kun Liu

University of Wollongong, hua@uow.edu.au

A. Polyanskii

University of Wisconsin, Madison, USA

W. M. Chen

University of Wollongong

Y. C. Guo

University of Wollongong, yanhui@uow.edu.au

S. X. Dou

University of Wollongong, shi@uow.edu.au

See next page for additional authors

Follow this and additional works at: https://ro.uow.edu.au/engpapers

Part of the Engineering Commons

https://ro.uow.edu.au/engpapers/20

\section{Recommended Citation}

Liu, Hua-Kun; Polyanskii, A.; Chen, W. M.; Guo, Y. C.; Dou, S. X.; and Apperley, M.: Magneto-optical images of Ag/Bi-2223 tapes processed by flat rolling, "sandwich" rolling and pressing 2001.

https://ro.uow.edu.au/engpapers/20

Research Online is the open access institutional repository for the University of Wollongong. For further information contact the UOW Library: research-pubs@uow.edu.au 


\section{Authors}

Hua-Kun Liu, A. Polyanskii, W. M. Chen, Y. C. Guo, S. X. Dou, and M. Apperley 


\title{
Magneto-Optical Images of $\mathrm{Ag} / \mathrm{Bi}-2223$ Tapes Processed by Flat Rolling, "Sandwich" Rolling and Pressing
}

\author{
Hua K. Liu, Anatolii Polyanskii, Wu M. Chen, Yuan C. Guo, Shi X. Dou, Miles Apperley
}

\begin{abstract}
Magneto-optical imaging (MOI) has been used for study $\mathbf{A g} / \mathbf{B i}-2223$ tapes processed using flat rolling, "sandwich" rolling, and pressing methods for the intermediate mechanical deformation in powder-in-tube process. The results show that not only the density of the microcracks but also their distribution affect $\boldsymbol{J}_{\mathrm{c}}$. Rolled tapes have a higher density of microcracks than pressed tapes. Although the flat rolled tape and "sandwich" rolled tape have the same level density of microcracks at the same reduction, the cracks in the former are more in the transverse direction than in the latter. In all three cases, $J_{c}$ reaches a maximum value at an optimal reduction rate.
\end{abstract}

Key words-Magneto-optical imaging, "sandwich" rolling, Ag/Bi-2223 multifilamentary tapes, microcracks.

\section{INTRODUCTION}

$\mathrm{M}$ agneto-optical imaging (MOI) has proved to be an effective technique in the study of the current distribution within conductors. MOI has been used for studying the patterns of flux penetration into $\mathrm{Ag} / \mathrm{Bi}-2223$ multifilamentary tapes [1]. MOI reveals the tendency of flux to enter filaments in regular patterns transverse to the rolling direction, with periods that vary depending on the architecture of the tape. On subsequent dissolution of the silver matrix and ultrasonic agitation of the filament bundle, it is seen that there is a strong correlation between the

Manuscript received 18th August 2000. (This work was supported by Australian Research Council, Department of Education, Training and Youth Affairs, and Australian Superconductors Ltd, Project Id (F89905267 and A10012023). At the University of Wisconsin-Madison this work was supported by DOE-EERE

H.K. Liu is with the Institute for Superconducting and Electronic Materials, University of Wollongong, Wollonong, NSW 2522 Australia (telphone: 61 2-4221 -4547, e-mail: hua liu(guow.edu.au)

A. Polyanskii is with the Applied Superconductivity Center, University of Wisconsin-Madison, WI 53706, USA (telphone: 1 608-265-5455, email: polyansk(oengr.wisc.ediu)

W.M. Chen Y.C. Guo and S.X. Dou are with the Institute for Superconducting and Electronic Materials, University of Wollongong, Wollonong, NSW 2522 Australia, W.M. Chen is on leave from Department of Physics, Nanjing University, P.R. China (telphone: 61 2- 4221-5798, email: chen@uow.edu.au)

M. Apperley is with Australian Superconductors, Engineering and Innovation Education Centre, Coniston, NSW 2500 Australia (telphone: 61 2-4226-5331, e-mail: milesa@ozemail.comau flux entry period and the tendency of the filaments to crack. The lengths of the uncracked filaments vary from about 0.2 $-0.5 \mathrm{~mm}$. This result has been found in even very high $J_{\mathrm{c}}$ tapes $\left(\mathrm{J}_{\mathrm{c}}(77 \mathrm{~K}, 0 \mathrm{~T}), 50-60 \mathrm{kA} / \mathrm{cm}^{2}\right)$ [1]. It has been proposed that the cracks are remains of the unhealed damage produced during the rolling required to density the $\mathrm{Bi}-\mathrm{Sr}-\mathrm{Ca}-\mathrm{Cu}-\mathrm{O}$ filaments after partial reaction from the $\mathrm{Bi}$ 2212 to $\mathrm{Bi}-2223$ phase [2]. By extracting the filaments from the finished tape, we found that the $J_{c}$ of individual filaments can vary from the centre to the edge of the tape by more than a factor of 5 for rolled tape [3]. It is clear from the MO images that the distribution of the cracks is not homogeneous and constitutes a barrier to the current flow. The performance of the $\mathrm{Ag} / \mathrm{Bi}-2223$ tapes should thus be further improved by better controlling the deformation conditions and the liquid phase to reduce and/or heal the cracks.

The extent and distribution of the cracks are strongly dependent on the reduction rate and the techniques used for the intermediate deformation $[4,5]$. In our previous work, a "sandwich rolling" process was developed to prevent the formation of sausaging and cracks in the longitudinal direction in Ag-clad $\mathrm{Bi}$-based composite tapes, fabricated by using the powder-in-tube method [2]. It has been found that flat-rolled tapes have many more microcracks in the transverse direction than the "sandwich" rolled tapes and that the maximum $\mathfrak{J}_{\mathrm{c}}$ of "sandwich" rolled tape is $35 \%$ higher than for flat-rolled tape [6]

In this paper, the effect of the reduction rate on microstructure and $\mathrm{J}_{\mathrm{c}}$ for flat rolled, pressed and "sandwich" rolled $\mathrm{Ag} / \mathrm{Bi}-2223$ tapes was studied using magneto-optical imaging technique.

\section{EXPERIMENTAL}

Multi-filamentary $\mathrm{Ag} / \mathrm{Bi}-2223$ tapes were fabricated by using the powder-in-tube method. Thermo-mechanical processing was carried out using two thermo-cycle heattreatments with an intermediate deformation [7].

The rolled long tape was sintered at $840^{\circ} \mathrm{C}$ for $50 \mathrm{~h}$ in air and furnace-cooled to room temperature. Short tapes (nonintermediate-deformed) with the same length cut from the same long tape were systematically deformed in thickness with total reduction rates from $0 \%$ to about $35 \%$ by using the three processes: flat rolling (or normal rolling), "sandwich" rolling and pressing. The "sandwich" rolling was performed with the tape sandwiched between two 0.9 
$\mathrm{mm}$ thick spring-steel plates and rolled with a varying reduction rate in the longitudinal direction. After the reduction procedure, samples were sintered in air at $840^{\circ} \mathrm{C}$ for $50 \mathrm{~h}$, followed by an annealing procedure at $825^{\circ} \mathrm{C}$ for $30 \mathrm{~h}$.

The details of systematic characterizations on welldefined tape samples will be reported elsewhere [6]. The relative core densities of the samples were determined by choosing the core density of non-intermediate-deformed tape as a reference. To determine the volumes of as-sintered samples, the length, width and thickness of the samples were measured with a vernier micrometer, and the volumes of the tapes subjected to the varying reduction rate were calculated. If the core mass of a sample is known, the core density is easy to get by calculating the mass divided by the volume. Since all the samples have the same core mass, it is possible for us to determine the relative core densities without measuring the core mass. It is very simple to get the relative core density of a deformed sample, using the reciprocal volume of the non-intermediate-deformed sample divided its reciprocal volume. It is reasonable to believe that the relative core density changes represent the changes in the absolute density.

Some tape samples were further investigated using magneto-optical imaging at the University of WisconsinMadison. Samples were prepared for MO imaging by chemically removing the silver sheath as described previously [4]

\section{RESULTS AND DISCUSSION}

\section{A. "Sandwich" rolled tapes at different reduction rate}

There is an optimal reduction rate for pressed, normal rolled and "sandwich" rolled tapes [6]. The $J_{c}$ of the tapes resulting from the three different processes is initially increased with increases in the reduction rate, reaches a peak at the optimal reduction rate and then decreases for larger reduction rates.

Fig. 1 shows the MO images for the tapes processed at three different reduction rates $(8 \%, 23 \%$ and $34 \%$ ) using the "sandwich" rolling technique. At a low reduction rate (8\%) the MO image of "sandwich" rolled tape shows a random flux penetration due to the low physical density (Fig. 1a). Thus $J_{c}$ is low, $10 \mathrm{kA} / \mathrm{cm}^{2}\left(I_{c}=28 \mathrm{~A}\right)$. At a large reduction rate $(34 \%)$, the MO image of "sandwich" rolled tape clearly shows a high density of flux penetration running across the filaments (Fig. 1c). The high density of flux penetration represents a high density of microcracks, which block the current flow, resulting in a low $\mathrm{J}_{\mathrm{c}}\left(\mathrm{I}_{\mathrm{c}}=30 \mathrm{~A}, \mathrm{~J}_{\mathrm{c}}=12\right.$ $\left.\mathrm{kA} / \mathrm{cm}^{2}\right)$. At an optimal reduction rate $(23 \%)$ the tape has the highest $J_{c}\left(I_{c}=44 A, J_{c}=18 \mathrm{kA} / \mathrm{cm}^{2}\right)$. With increasing

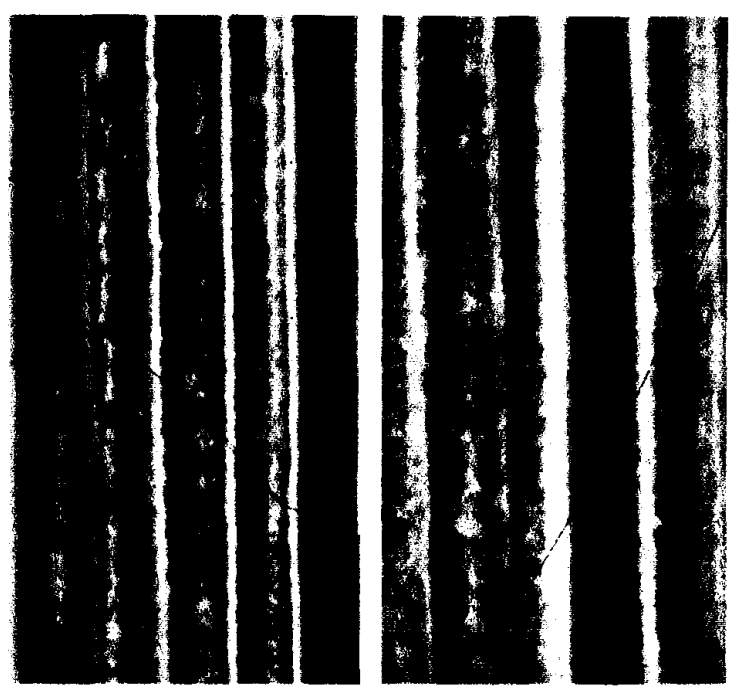

1a

$1 \mathrm{~b}$

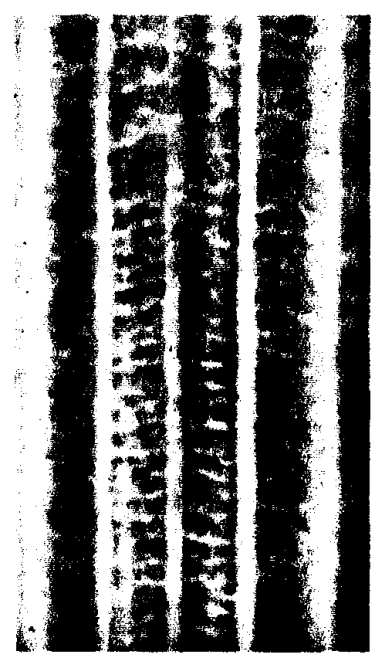

$1 \mathrm{c}$

Fig. 1. $\mathrm{MO}$ images (taken at $\mathrm{ZFC}, \mathrm{T}=12 \mathrm{~K}, \mathrm{H}=60 \mathrm{mT}$ ) for the tapes processed at three different reduction rates: $8 \%\left(\mathrm{I}_{\mathrm{c}}=28 \mathrm{~A}, 10 \mathrm{kA} / \mathrm{cm}^{2}\right.$, Fig. 1a), $23 \%\left(I_{c}=44 \mathrm{~A}, J_{c}=18 \mathrm{kA} / \mathrm{cm}^{2}\right.$, Fig. $\left.1 \mathrm{~b}\right)$ and $34 \%\left(I_{c}=30 \mathrm{~A}, J_{\mathrm{c}}=12\right.$ $\mathrm{kA} / \mathrm{cm}^{2}$, Fig. 1c) using "sandwich" rolling technique.

reduction rate the relative density of the oxide core increases through elimination of the pores. At the optimal reduction rate the relative core density reaches a maximum value. Further increases the reduction causes cracks to form over the remaining pores, actually causing decreases in relative core density. 


\section{B. Normally rolled and pressed tapes at the same reduction} rate

Fig. 2 shows magneto-optical images for rolled and pressed tapes at the optimal reduction rate of $20 \%$. It is evident that the patterns for flux penetration in the two samples are very different. In the rolled tape, flux has penetrated transversely across the entire tape core with an almost equal spacing, representing the distribution patterns of the unhealed cracks (Fig. 2a). By carefully examining the MO image of the pressed tape, we can see clearly one or two elongated, thin and light stripes running parallel to the longitudinal tape direction (Fig. 2b). It is also noted that there are more microcracks in the rolled tape than the pressed tape. As the transverse cracks will block the current flow it is expected that the $J_{c}$ of the rolled tape will be lower than for the pressed one. The transport measurements have confirmed that the $J_{\mathrm{c}}$ of the pressed tape $\left(30 \mathrm{kA} / \mathrm{cm}^{2}\right.$, Fig. $2 b)$ was double that for the flat rolled tape $\left(14 \mathrm{kA} / \mathrm{cm}^{2}\right.$, Fig. 2a). These results are consistent with previous reports based on SEM, optical microscopy [2] and MOI $[4,5]$.

\section{Normal rolled and "sandwich" rolled tapes at the same reduction rate}

Fig. 3 shows MO images for not deformed, flat rolled and sandwich rolled tapes. Not deformed tape means that there is no intermediate deformation. The MO image shows a random penetration of flux due to the high porosity (Fig. 3a,

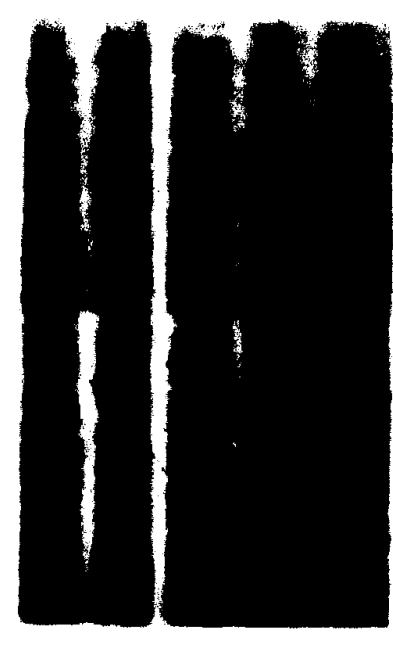

$2 a$

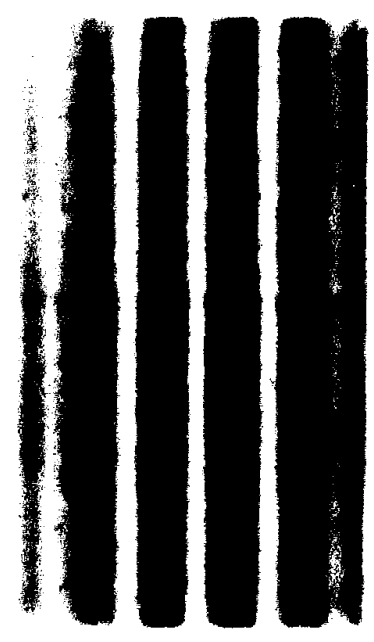

$2 b$
Fig. 2. Magneto-optical images (taken at $\mathrm{ZFC}, \mathrm{T}=10 \mathrm{~K}, \mathrm{~B}=60 \mathrm{mT}$ ) for rolled $\left(J_{c}=14 \mathrm{kA} / \mathrm{cm}^{2}\right.$, Fig. $\left.2 \mathrm{a}\right)$ and pressed $\left(J_{c}=30 \mathrm{kA} / \mathrm{cm}^{2}\right.$, Fig. $\left.2 \mathrm{~b}\right)$ tapes at the optimal reduction rate of $20 \%$.

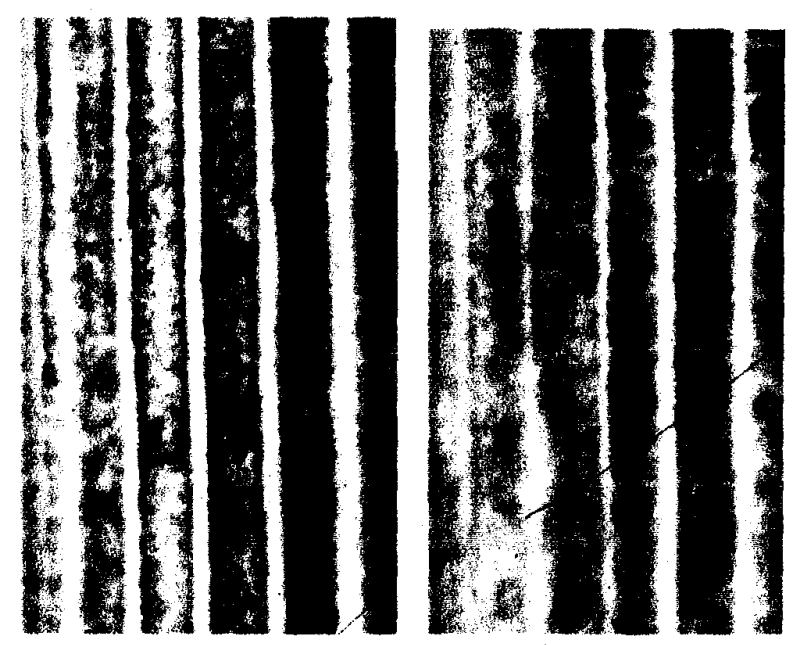

$3 a$ $3 b$

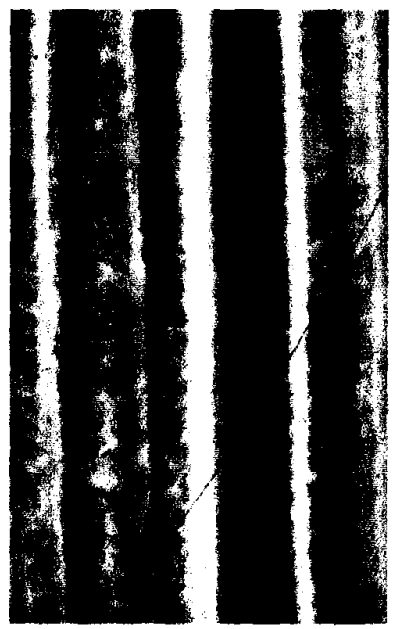

$3 c$

Fig. 3. MO images (taken at $\mathrm{ZFC}, \mathrm{T}=12 \mathrm{~K}, \mathrm{H}=60 \mathrm{mT}$ ) for not deformed $\left(\mathrm{J}_{\mathrm{c}}=7 \mathrm{kA} / \mathrm{cm}^{2}\right.$, Fig. $3 \mathrm{a}$ ), flat rolled (Fig. $3 \mathrm{~b}$, reduction rate $23 \%, \mathrm{~J}_{\mathrm{c}}=13$ $\mathrm{kA} / \mathrm{cm}^{2}$ ) and sandwich rolled (Fig, $3 \mathrm{c}$, reduction rate $23 \%, \mathrm{~J}_{\mathrm{c}}=18 \mathrm{kA} / \mathrm{cm}^{2}$ ) tapes.

$\mathrm{J}_{\mathrm{c}}=7 \mathrm{kA} / \mathrm{cm}^{2}$, reduction rate $0 \%$ ) in this sample as a result of 2223 grain growth. $J_{c}$ is very low due to the low relative density. Both the flat rolled tape and sandwich rolled tape are at the optimal reduction rate while the $J_{c}$ for the latter is $35 \%$ higher than for the former. The MO images show that there are more transverse microcracks in the flat rolled tape (Fig. $3 \mathrm{~b}$, reduction rate $23 \%, \mathrm{~J}_{\mathrm{c}}=13 \mathrm{kA} / \mathrm{cm}^{2}$ ) than in the "sandwich" rolled tape (Fig. $3 \mathrm{c}$, reduction rate $23 \%, \mathrm{~J}_{\mathrm{c}}=18$ 
$\mathrm{kA} / \mathrm{cm}^{2}$ ). This explains why the $J_{c}$ of "sandwich" rolled tape is higher than for normal rolled tape at the same reduction rate.

\section{Pressed and "sandwich" rolled tapes}

The expansion direction due to deformation is similar in the pressed and "sandwich' rolled tapes, largely perpendicular to the length of the tape [2]. MO images show that the density of microcracks produced by "sandwich" rolling (5\% reduction, Fig. 4a) is almost the same as for pressing (reduction $10 \%$, Fig. 4b). It is consistent with the transport measurements that the "sandwich" rolled and pressed tapes have nearly the same $J_{c}$ of $15 \mathrm{kA} / \mathrm{cm}^{2}$ and $17 \mathrm{kA} / \mathrm{cm}^{2}$, respectively. So, the results for "sandwich" rolling are nearly as good as those achieved by pressing even though the reduction rate $(10 \%)$ for the pressing is twice that $(5 \%)$ for the "sandwich" rolling.

\section{CONCLUSIONS}

The results of transport measurements and the $\mathrm{MO}$ imaging technique were used to study the effect of the deformation rate on tapes processed by using pressing, flat rolling and "sandwich" rolling. In all three cases the $J_{c}$ increased with increasing reduction, reached a maximum value at an optimal reduction rate and decreased on further increases in the reduction rate. At the same reduction rate,

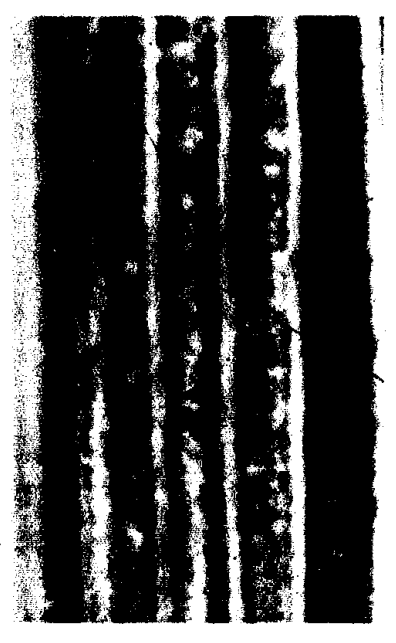

$4 \mathrm{a}$
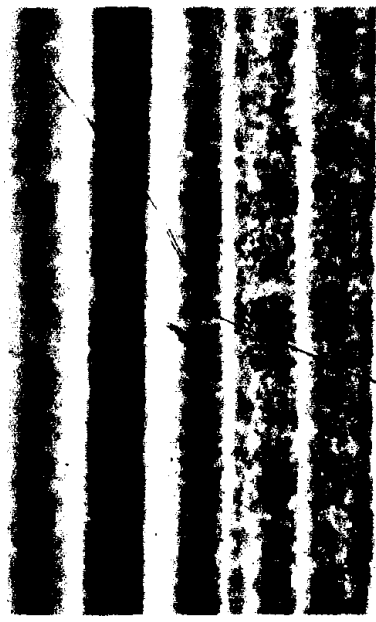

$4 b$
Fig. 4. MO images (taken at $\mathrm{ZFC}, \mathrm{T}=12 \mathrm{~K}, \mathrm{H}=60 \mathrm{mT}$ ) for "sandwich" rolled (Fig. 4a, reduction rate $5 \%, J_{c}=15 \mathrm{kA} / \mathrm{cm}^{2}$ ) and pressed (Fig. 4b, reduction rate $10 \%, \mathrm{~J}_{\mathrm{v}}=17 \mathrm{kA} / \mathrm{cm}^{2}$ ) tapes. flat rolling caused more cracks in the transverse direction in the tape core than sandwich rolling as evidenced by the flux penetration across the transverse core of the filaments in the former. The quality of "sandwich" rolled tape is as good as for pressed tape and better than for flat rolled tape. The sandwich rolling techniques can be easily scaled up for fabricating tapes in long lengths and large quantities.

\section{ACKNOWLEDGMENT}

The authors from the University of Wollongong wish to thank the Australian Research Council, Department of Education, Training and Youth Affairs, and Australian Superconductors Ltd for financial support (Project Id: F89905267 and A10012023). The author from the University of Wisconsin-Madison wishes to thank DOEEERE and NSF for financial support. We wish to thank Professor D.C. Larbalestier for his comment on the manuscript and support this work at the University of Wisconsin-Madison.

\section{REFERENCES}

[1] X.Y. Cai, A. Polyanskii, Q. Li, G.N. Riley Jr and D.C. Larbalestier "Current-limiting mechanisms in individual filaments extracted from superconducting tapes", Nature Vol. 392, pp. 906-909, Apr. 1998

[2] W.G. Wang, H.K. Liu, Y.C. Guo, P. Bain and S.X. Dou, "Mechanism of deformation and sandwich rolling process in Ag-clad Bi-based composite tapes", Applied Superconductivity, Vol. 3, No. 11/12, pp. 599605,1995

[3] Y.C. Guo, W.M. Chen, H.K. Liu, S.X. Dou and A.V. Lukashenko "Improved uniformity of microstructure and electrical properties of Bi2223/Ag superconducting tapes", Physica C, submitted.

[4] J.A. Parrell, A.A. Polyanskii, A.E. Pashitski and D.C. Larbalestier, "Direct evidence for residual, preferentially-oriented cracks in rolled and pressed Ag-clad BSCCO-2223 tapes and their effect on the critical current density", Supercond. Sci. Technol. Vol. 9, No 5, pp.393-398, 1996

[5] J. Anderson, X.Y. Cai, M. Feldmann, A. Polyanskii, J. Jiang, J.A. Parrell, K.R. Marken, S. Hong and D.C. Larbalestier, "The influence of intermediate roll characteristics on the residual crack density and critical density in multifilamentary $\left(\mathrm{Bi}, \mathrm{Pb}_{2} \mathrm{Sr}_{2} \mathrm{Ca}_{2} \mathrm{Cu}_{3} \mathrm{O}_{x}\right.$ tapes", Supercond. Sci. Technol. Vol. 12, No. 9, pp. 617-623, 1999

[6] W.M. Chen, Y.C. Guo, G. McCaughey, M. Apperly, H.K. Liu and S.X. Dou, "Effect of various mechanical deformation techniques on critical current densities of $\mathrm{Ag} / \mathrm{Bi}-2223$ tapes", IEEE Trans. Appl. Supercond. Accepted for publication.

[7] S.X. Dou, R. Zeng, X.K. Fu, Y.C. Guo, J. Horvat, H.K. Liu, T. Beales and M. Apperley, "Critical role of phase transformation during processing of Ag/Bi:2223 tapes", IEEE Trans. Appl. Supercond. Vol. 9, No 2, 24362439,1999 